\title{
The Calculation of Computer Assisted Sun Shift Line Positioning
}

\author{
Zhao Xin, Zuo mengjin, Ma zhuang, Wu Jianhua \\ Tianjin University of Technology \\ Tianjin, P.R.China, 300384
}

\begin{abstract}
As the most important marine reserved system, astronomical positioning has incomparable advantages. In this paper, according to the basic principle of the sun shift line positioning, using the spherical triangle derives the mathematical model of the sun shift line positioning by observing the sun on the ship and then using the VB language works out the program of the sun shift line positioning. At last, the computer technique is applied to celestial navigation and is able to calculate the complex equations quickly. Through the practice, computer aided positioning not only meet the need of the navigation requirement, but also shorten the calculation time.
\end{abstract}

Keywords - celestial navigation, the sun shift line positioning, computer aided positioning

\section{INTRODUCTION}

The daytime is usually only observing the sun, so the sun shift line positioning is the main method of marine astronomical positioning. However, at present the sun shift line positioning is always used the altitude difference method proposed by French navigator St.Hilair in 1875 and this method needs to look up sailing calendar table and use calculator. Because the altitude difference method itself exists some error, such as mapping trival, calculation of complex, no timeliness. Traditional astronomical positioning limits the further development of the celestial navigation. In order to overcome these shortcomings, based on theory of astronomical positioning circle and according to the spherical triangle, we could establish mathematical models and works out the computer program. At last when we input observation datas, we can directly look up the ships positioning, latitude $\varphi$ and longitude $\lambda$ on the computer. With the application of computer technology, the traditional astronomical navigation to get rid of the shackles of height difference method become possible and then realize the automation of navigation.

\section{THE THEORY OF THE SUN SHIFT LINE POSITION AND MATHEMATICAL MODEL}

\section{A. The basic positioning theory}

The sun shift line positioning also is called "the different observation localization of the sun". In different time, the fore-and-aft observation of the sun positioning line is calculated and then with the shift line principle, we could get the method and process of the ship positioning. In the first observating the sun's altitude we can map one ship line of the sun and after a period of time, we can get the another shipline of the sun by observing the second altitude of the sun. We should parallelly move the first line of positioning along the ship's path to the second line of positioning in the observating transferring sun position line, and then the second ship line and the first tranfering ship line will make a point of intersection and this point of intersection is the second observation time of astronomical position.

\section{B. Establish mathematical model}

Because the ship is sailing on the sea, and each observation has certain time interval, it is necessary to make the ship line correct to the same time. When we are making some correction to celestial body's position, we can get revised celestial accurate position. At last, the correct mathematical model is established. More importantly, we need a large number of theoretical basis to verifiy that the mathematical model is accurate or not, so as to realize the sun shift line positioning accuracy. No revised mathematical model is shown in figure 1. Revised mathematical model is shown in figure 2. The target of revised mathematical model is unification of the observation times. 


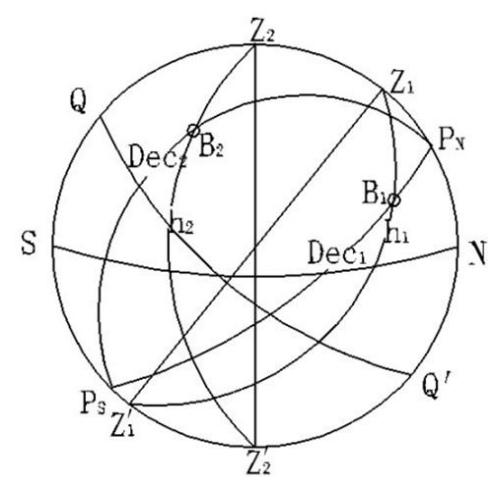

Figure 1. No revised mathematical model

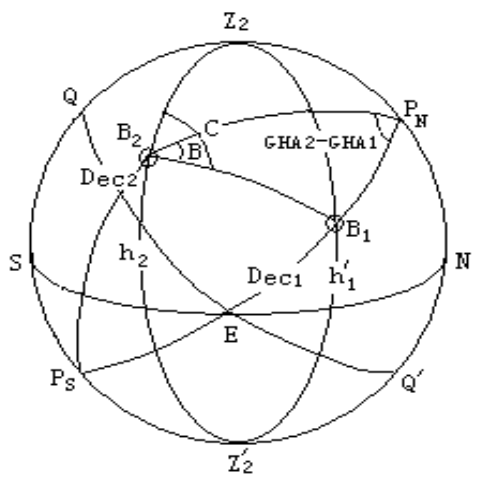

Figure 2. Revised mathematical model

Using the edge cosine formula in the spherical triangle $\mathrm{P}_{\mathrm{N}} \mathrm{Z}_{2} \mathrm{~B}_{2}$ :

$\varphi=\arcsin [\sinh 2 \sin \operatorname{Dec} 2+\cosh 2 \cos \operatorname{Dec} 2 \cos (\mathrm{C}-\mathrm{B})](1)$

$\mathrm{t}=\arccos \frac{\sinh 2-\sin \varphi \sin D e c 2}{\cos \varphi \cos D e c 2}$

$\mathrm{t}=\mathrm{t}_{\mathrm{G}} \pm \lambda$

*: East $\lambda$ is “ + "; West $\lambda$ is " - ".

C. The realization of the program

How to solve the model $\left(B_{1} B_{2}, B, C\right)$ is the key. In the spherical triangle $\mathrm{P}_{\mathrm{N}} \mathrm{B}_{1} \mathrm{~B}_{2}, \mathrm{Z}_{2} \mathrm{~B}_{1} \mathrm{~B}_{2}$ :

$\mathrm{B}_{1} \mathrm{~B}_{2}=\operatorname{arcos}[\sin \mathrm{Dec} 1 \sin \mathrm{Dec} 2$

$+\cos$ Dec1 $\cos ($ Dec2) $\cos ($ GHA2-GHA1)]

$$
\begin{aligned}
& B=\operatorname{arcos} \frac{\sin D e c 1-\sin D e c 2 \sin B_{1} B_{2}}{\cos D e c 2 \sin B_{1} B_{2}} \\
& C=\operatorname{arcos} \frac{\sin D e c 1-\sin D e c 2 \sin B_{1} B_{2}}{\cos D e c 2 \sin B_{1} B_{2}}
\end{aligned}
$$

Matters should be paid attention:

1) $h l^{\prime}=h 1+\frac{V\left(Z T_{2}-Z T\right) \cos \left(A_{1}-C A\right)}{60}$

$\mathrm{h} 1^{\prime}$ is the sun position of $\mathrm{B}_{1}$ that is correct to zenith $\mathrm{Z} 2$.

$A_{1}$ is the first sun's measured direction.

ZT1, ZT2 is the obervated time.

CA is the ship's course.

$\mathrm{V}$ is the speed of a ship.

2) The synonym of Dec and latitude $\varphi,+$; the different name of Dec and latitude $\varphi, \quad-$;

3) Before the upper meridian passage, $\mathrm{t}<0$; after the upper meridian passage, $\mathrm{t}>0$.

VB is a section of high visual programming language. We can use some simple control to realize the program editor, So we will reduce the calculation of the algorithm. Programming should be paid attention to: In VB there is only general trigonometric function and no inverse trigonometric function, we need to realize conversion through the trigonometric function transformation.

Program instructions in figure 3.



Figure 3. The sun shift line positioning program diagram 
VB basic program interface is shown in figure 4.

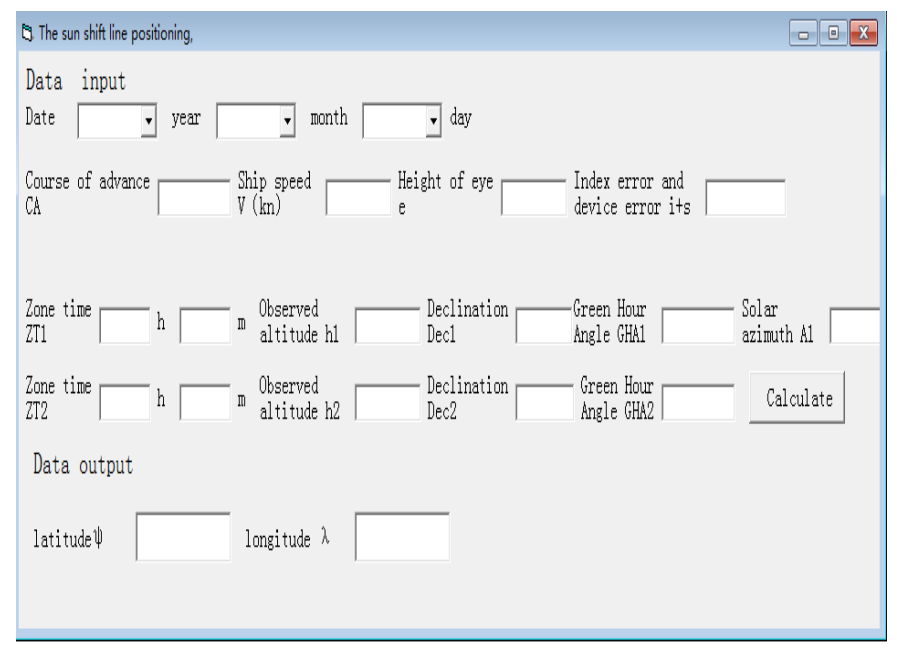

Figure 4. Basic program interface

\section{THE EXAMPLE OF THE SUN SHIFT LINE POSITIONING}

Verification: On 2009.02.15, Tianren ship set off from the Tianjin Xingang Port to Inchon Port on the $\mathrm{ZT}_{1} 12^{\mathrm{h}} 30^{\mathrm{m}}$. The course CA99 ${ }^{\circ}$, the speed V18kn, GMT1 $04^{\mathrm{h}} 30^{\mathrm{m}} 26^{\mathrm{s}}$, the first sun altitude $\mathrm{hs}_{1} 38^{\circ} 17^{\prime} .0$, the solar azimuth $\mathrm{A}_{1} 183^{\circ}$, the height of eye e $18 \mathrm{~m}$. On $\mathrm{ZT}_{2} 14^{\mathrm{h}} 18^{\mathrm{m}}$, GMT2 $06^{\mathrm{h}} 17^{\mathrm{m}} 40^{\mathrm{s}}$, the second sun altitude $31^{\circ} 29^{\prime} .5$. Index error and device difference $(\mathrm{i}+\mathrm{s})=0^{\prime} .0$. Solving the sun shift line position on $\mathrm{ZT}_{2} 14^{\mathrm{h}} 18^{\mathrm{m}}$ ?

Use mapping method:

$$
\begin{aligned}
& \mathrm{GHA}_{1} 244^{\circ} 04^{\prime} .6 \quad \mathrm{GHA}_{2} 270^{\circ} 53^{\prime} .1 \\
& \lambda_{\mathrm{c} 1} \quad \underline{118^{\circ} 06^{\prime} .0 \mathrm{E}} \quad \lambda_{\mathrm{c} 2} \quad \underline{118^{\circ} 42^{\prime} .0 \mathrm{E}} \\
& \mathrm{LHA}_{1} 362^{\circ} 10^{\prime} .6 \quad \mathrm{LHA}_{2} 389^{\circ} 35^{\prime} .1 \\
& 002^{\circ} 10^{\prime} .6 \quad 029^{\circ} 35^{\prime} .1
\end{aligned}
$$

Use the following formula:

$$
\begin{aligned}
& h_{c}=\sin ^{-1}\left(\sin \phi_{c} \cos \delta+\cos \phi_{c} \cos \delta \cos t\right) \\
& A_{c}=\cos ^{-1}\left(\tan \delta \cos \varphi_{c} \csc t-\sin \varphi_{c} \cot (t)\right)
\end{aligned}
$$
$\mathrm{A}_{1} \quad 183^{\circ}$
$\mathrm{A}_{2} \quad 214^{\circ}$

In the chart mapping the sun shift line position in figure 5.

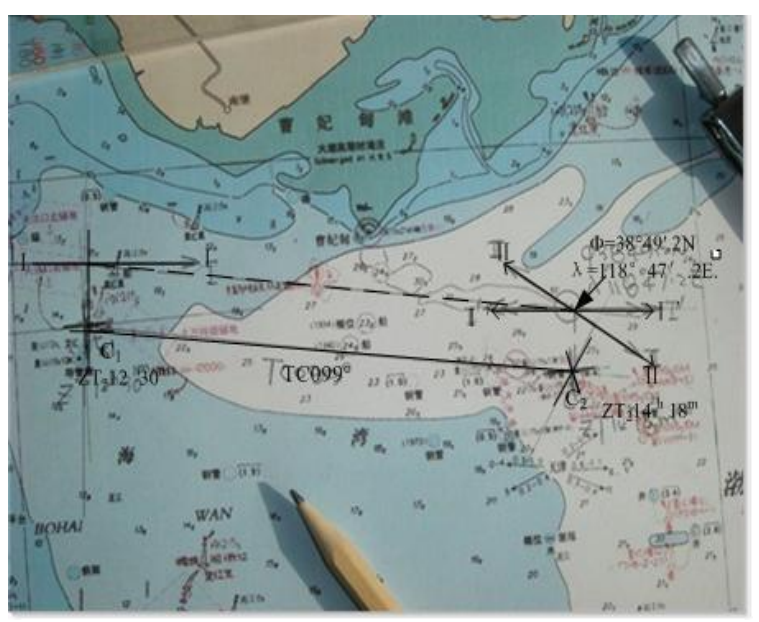

Figure 5. Mapping method data

From the above figure:

$\varphi=38^{\circ} 49^{\prime} .2 \mathrm{~N}, \lambda=118^{\circ} 47^{\prime} .2 \mathrm{E}$.

Use computer aided positioning:

Input data: After correction, observation height $h_{s}$ draw true height h. According to the Greenwich mean time, we could check the nautical almanac to get the sun coordinates, Declination(Dec) and Greenwich hour angle(GHA):

\section{$\mathrm{h}_{1} 38^{\circ} 24^{\prime} .6$ Dec $112^{\circ} 38^{\prime} .4$ S GHA1 $244^{\circ} 04^{\prime} .6$. \\ $\mathrm{h}_{2} 31^{\circ} 36^{\prime} .8$ Dec2 $12^{\circ} 36^{\prime} .9 \mathrm{~S}$ GHA2 $270^{\circ} 53^{\prime} .1$.}

The above 11 data $\left(\mathrm{ZT}_{1}, \mathrm{ZT}_{2}, \mathrm{~V}, \mathrm{CA}, \mathrm{hs}_{1}, \mathrm{hs}_{2}\right.$, Dec1, Dec2, GHA1, GHA2, $A_{1}$ ) input program interface, and we should click the calculate button, some calculation results will be shown in figure 6.

On $\mathrm{ZT} 14^{\mathrm{h}} 18^{\mathrm{m}}$ the sun shift line position:

$\varphi=38.478007723 \approx 38^{\circ} 28 .^{\prime} 68 \mathrm{~N}$

$\lambda=119.34358195 \approx 119^{\circ} 20^{\prime} .61 \mathrm{E}$

Solution is obtained:
$\mathrm{h}_{1} 38^{\circ} 24^{\prime} .6$
$\mathrm{h}_{2} \quad 31^{\circ} 35^{\prime} .5$
$\mathrm{h}_{\mathrm{c} 1} \underline{38^{\circ} 28^{\prime} .2}$
$\mathrm{h}_{\mathrm{c} 2} \quad \underline{31^{\circ} 31^{\prime} .9}$
$\Delta \mathrm{h}_{1}-3^{\prime} .4$
$\Delta \mathrm{h}_{2}-3^{\prime} .6$ 


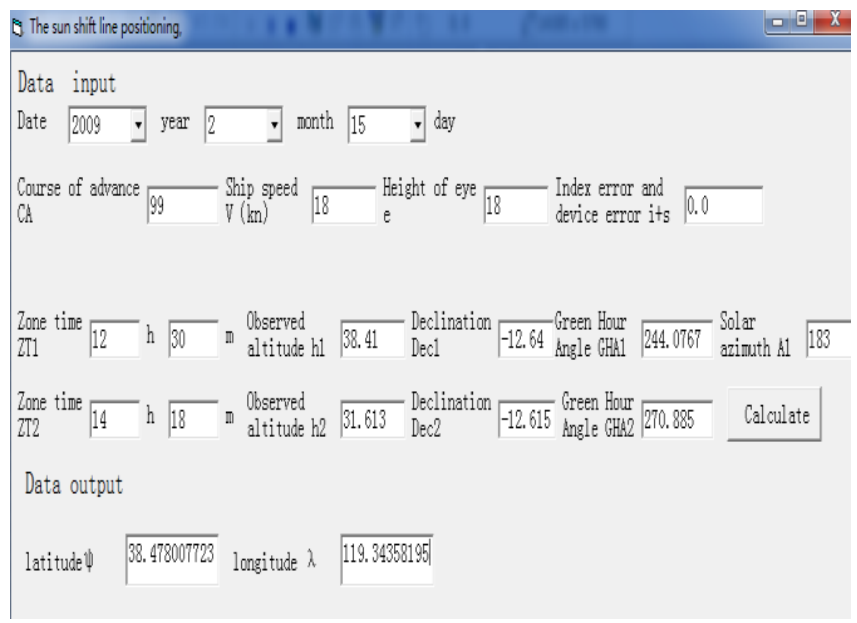

Figure 6. Running program

GPS showing the ship position:

$\varphi=38^{\circ} 24^{\prime} .7 \mathrm{~N}, \lambda=119^{\circ} 15^{\prime} .9 \mathrm{E}$.

Data comparison in table 1:

Table 1. data comparison

\begin{tabular}{|c|c|c|c|}
\hline & mapping & computer & GPS \\
\hline \multirow{2}{*}{ data } & $\varphi=38^{\circ} 49^{\prime} .2 \mathrm{~N}$ & $\varphi=38^{\circ} 28 .^{\prime} 68 \mathrm{~N}$ & $\varphi=38^{\circ} 23^{\prime} .7 \mathrm{~N}$ \\
& $\lambda=118^{\circ} 47^{\prime} .2 \mathrm{E}$ & $\lambda=119^{\circ} 20^{\prime} .61 \mathrm{E}$ & $\lambda=119^{\circ} 15^{\prime} .9 \mathrm{E}$ \\
\hline error & $26^{\prime}$ & $4^{\prime}$ & 0 \\
\hline
\end{tabular}

Through the comparison among three datas, accuracy of GPS position is the highest, that is used as the benchmark. Accuracy of the mapping method is the lwoest, its error area is about $26^{\prime}$, that is about $26 \mathrm{kn}$. Chart of the location area is within a position circle of the radius of $26 \mathrm{kn}$. Accuracy of the computer aided positioning method is smaller than mapping method, its error area is only $4^{\prime}$, that is about $4 \mathrm{kn}$. Computer aided positioning of the location area is within a position circle of the radius of $4 \mathrm{kn}$ positioning and precision meet the requirements. Computer aided astronomical positioning can get close to actual position more accurately, error can be controlled in the acceptable range and positioning accuracy has been greatly improved. It will take about 15 minute to finish position by mapping position method and few second to finish position by computer aided positioning method. We can realize rapid positioning.

\section{CONCLUSION}

The importance of computer technology to astronomical navigation development:
1) Greatly improve the efficiency and accuracy of calculation: Inputting data only 1 minute can complete the sun shift line positioning, calculation and mapping error does not need to consider and the computer calculation accuracy completely satisfy the navigation requirements.

2) The complicated astronomical calculation is completed by the computer, so traditional astronomical positioning won't make crew flinch and easily increase the crew interest. Since using computer calculation, the sun shift line positioning accuracy depends on the observation error of the solar altitude. As long as we practice more, the crew's personal capacity will gradually improve.

3) Through the comparison with GPS, the sun shift line positioning system error can gradually be mastered and finally eliminated. Within the stable scope of the permission of astronomical position error (smaller random error), we even can use astronomical position to insteal of GPS when GPS does not work well. Maybe this is why astronomical nvigation still be widely used today even modern ship equipement GPS.

The huge advantage of astronomical positioning has gotten the attention. However, computer hardware and software are ever improving and the requirements for positioning accuracy becomes more and more strict. In order to make the ship safety, marine technology must make use of the benefits of computer revolution, and realize constant localization and truly realize marine automation.

\section{REFERENCES}

[1] Zou xiao, Visual Basic,China Machine Press,2008.12

[2] Liu Dexin, Navigation Study, Dalian Maritime University Press, 2011.1

[3] Ma zhuang, Calculate astronomical positions using spherical trigonometry. 7th Navigation Technology, 2004

[4] Purple Mountain Observatory, Chinese Academy of Science. The Chinese Astronomical Calendar for 2009 Year [M ]. Beijing: Publishing House of Science, 2009.(in Chinese)

[5] Zhu Xiaohong,Xu Rui,Zhang Junyan, The current construction situation and future development of Celestial navigation standard system, Geospatial information, 2011.6

[6] Zhao Xin, Ma Zhuang, Jia Haihong. Computer-Aided Double Celestial-Body Positioning and Accuracy Analysis, 2012 2nd International Conference on Remote Sensing, Environment and Transportation Engineering, 2012 